\title{
Information Variables for the Predictability of Future Changes in Real Growth
}

\author{
Tae Ho Kim ${ }^{a, 1} \cdot$ Jae Hwa Jung ${ }^{a} \cdot$ Min Jeong $\operatorname{Kim}^{a}$ \\ ${ }^{a}$ Department of Information Statistics, Chungbuk National University \\ (Received December 14, 2012; Revised February 15, 2013; Accepted February 26, 2013)
}

\begin{abstract}
It has been interested in developing useful information variables that are able to predict the future movement of final objects to attain the specific policy and strategic target. Term structure of interest rates is known as an important variable to predict future business and economic activity, yet there is little empirical work on the predictability of future changes in real output. This study attempts to develop the statistical model and examine whether domestic term structure of interest rates can predict variations of future cumulative changes in real growth on a long time horizon.
\end{abstract}

Keywords: Information variable, predictability, term structure.

\section{1. 서론}

최근 국내 경기 침체가 장기화 되고 폐해가 모든 분야에 걸쳐 확산됨에 따라 경기 예측의 중요성이 주요 사회문제로 떠오르게 되었다. 특히 국내 경기순환의 주기가 전에 비해 짧아지고 불규칙해 예측이 어려 워졌으며 이에 따라 현실 상황에 적합한 정책 목표의 달성에 차질을 빚게 되었다. 특정 정책 목표를 달 성하는데 있어서 정부는 현실적으로 최종 목표에 직접 영향을 미치기는 어려우며 정책수단을 통해 간접 적인 영향력만 발휘할 수 있을 뿐이다. 그러나 정책수단의 조절을 통해 최종 목표에 영향을 주기까지에 는 시차가 존재하고 파급경로도 불확실하므로 최종 목표의 미래 동향을 예측할 수 있는 유용한 정보변수 의 개발에 관심을 가지게 된다. 정보변수란 최종 목표에 대해 선행적 상관관계를 가진 지표로 최종 목표 의 미래 움직임을 예측하는데 유용한 정보를 제공하는 변수이다.

미래 경기동향의 예측에 유용한 정보를 주는 것으로 알려진 장단기 금리차는 미국, $\mathrm{EU}$ 등 선진국에서 경기상황 예측을 위한 선행지표로 활용되어 왔으며, 우리나라에서도 통계청의 경기선행지수 산정 항목 에 포함하고 있다. Estrella와 Mishkin (1996)은 미국의 경기 불황 예측에서 다른 변수들에 비해 장기 시계에서 장단기 금리차가 우월함을 보이면서 예측도구로서의 효용성을 입증하였다. 일반적으로 장기 금리는 단기금리보다 높으며 장단기 금리가 전도되면 경기 침체가 뒤따르고, 회복되면 경기 상승의 전 조가 되는 것으로 알려져 있어서 장단기 금리차가 실질 경기순환 예측에 중요한 변수로 간주된다. 단기 금리는 경기변동과 통화정책에 의해 영향을 받고, 장기금리는 미래의 예상 단기금리와 기간 프리미엄의 변화에 따라 달라지므로 장단기 금리차에는 현재와 미래의 정책 변화 또 미래의 경기동향에 대한 정보

\footnotetext{
${ }^{1}$ Corresponding author: Professor, Department of Information Statistics, Chungbuk National University, 410 Seongbong-Ro, Heungduk-Gu, Cheongju, Chungbuk 361-763, Korea. E-mail: thkim@chungbuk.ac.kr
} 
가 담겨지게 된다. 이러한 이론적 근거에 의해 장단기 금리차와 미래 경기 간에는 통계적 연관관계가 존 재할 것으로 기대되며, 이 경우 장단기 금리차는 장단기 미래의 경기 예측에 정보변수로 활용될 수 있을 것이다.

Lee (1996)와 Oh (1997)는 장단기 금리차가 경기와 인플레이션 예측에 유용하게 기능함을 보였다. Kim과 Song (2009)은 장단기 금리차가 증가하면 경기 하강의 확률이 감소하며, 특히 금리차와 경기 지수는 정의 상관관계에 있고 금리차의 확대는 경기 상승, 축소는 경기 하락과 밀접한 연관이 있음을 확 인하였다. 우리나라의 경우 전에는 금리 규제와 같은 제도적 제약으로 인해 금리차가 갖는 의미가 제한 적이었으나 그간 추진되어온 금리자율화로 인해 장단기 금리차를 정의하고 미래 경기동향에 대한 예측 력 검정에 이용하는데 가능한 여건을 갖추게 되었다. 장단기 금리차의 경기 예측력을 결정하는 데는 적 절한 장단기 금리차의 선택과 필요한 시계열자료의 확보 등 여러 난점이 존재한다. 본 연구에서는 국내 장단기 금리차가 미래의 성장에 대한 정보변수로 활용될 수 있는지 판별하기 위한 통계적 검정을 실시한 다. 따라서 국내에서 널리 사용되는 기간구조를 적용시켜 이들이 미래의 성장에 대해 예측력을 갖는지, 얼마나 가까운 그리고 먼 미래에 대해 유의한 예측력을 갖는지 추정하고 결과를 분석해 보고자 한다.

\section{2. 모형}

실물지표의 동향을 장단기 금리차로 예측하고 이들 간 관계를 검정하기 위한 방법은 세 가지로 구분할 수 있다. 첫째, probit 모형을 사용하여 금리차로 불황이 올 확률을 예측하는 방법으로 다음의 모형을 사용한다.

$$
P\left(R_{t+k}=1 \mid x_{t}\right)=F\left(\beta^{\prime} x_{t}\right),
$$

여기서 $F$ 는 표준누적정규확률밀도함수이며, 또 $R_{t}$ 는 불황일 때는 1 , 호황일 때는 0 이 된다. 위 모형의 우도함수는 아래와 같다.

$$
L=\prod_{R_{t+k}=1} F\left(\beta^{\prime} x_{t}\right) \prod_{R_{t+k}=0}\left[1-F\left(\beta^{\prime} x_{t}\right)\right] .
$$

우도함수를 미지의 모수에 대해 최대화시키면 추정값과 pseudo- $R^{2}$ 값을 얻게 된다 (Kim과 Song, 2009; Lee, 2010). Estrella와 Mishkin (1996, 1998)은 미국 경제의 불황 여부를 예측하기 위한 probit 모형을 개발하였으며, 이들의 모형은 4 분기 후의 불황을 예측할 수 있음을 확인하였다. $\operatorname{Kim}$ 등 (2004)는 장단기 금리차의 예측력을 이용하여 probit 모형으로 금리차 수준에 따른 침체도래 확률을 구 하고 주식시장에서 마켓타이밍 전략이 유용한지를 분석하였다. 그 외 probit 모형을 사용한 연구로는 Smith와 Naylor (2001), Resnick과 Shoesmith (2002), Kim과 Song (2009)이 있으며, Boldin (1994)은 이들과는 달리 불황을 구조변화의 형태로 모형에 설정하는 접근법을 사용하였다.

둘째, 벡터자기회귀모형을 사용하여 Granger 인과성 검정, 분산분해 및 충격반응함수 분석 등을 실시하 여 상호 동태적 관계를 검정하는 방법이다. Granger 검정은 평균 0 인 선형 정상확률과정에서 $\varepsilon_{k}(t)$ 가 $Z_{1}(t)$ 만 사용했을 때의 오차항이고 $\varepsilon_{k}^{*}(t)$ 는 $Z_{1}(t)$ 와 $Z_{2}(t)$ 를 함께 사용했을 때의 오차항이라면 아래와 같을 때 $Z_{2}(t)$ 는 $Z_{1}(t)$ 의 예측에 유용하다 (Granger, 1986).

$$
\lim _{k \rightarrow \infty} \inf E\left|\varepsilon_{k}(t)\right|^{2}>\lim _{k \rightarrow \infty} \inf E\left|\varepsilon_{k}^{*}(t)\right|^{2} .
$$

Granger의 정의는 아래와 같이 자기회귀형으로 표현된다.

$$
\alpha_{11}(0) Z_{1}(t)=\sum_{k=1}^{\infty} \alpha_{12}(k) Z_{1}(t-k)+\sum_{k=1}^{\infty} \alpha_{13}(k) Z_{2}(t-k)+\varepsilon_{1}(t),
$$




$$
\alpha_{21}(0) Z_{2}(t)=\sum_{k=1}^{\infty} \alpha_{22}(k) Z_{1}(t-k)+\sum_{k=1}^{\infty} \alpha_{23}(k) Z_{2}(t-k)+\varepsilon_{2}(t),
$$

여기서 두 오차항 $\varepsilon_{1}(t)$ 와 $\varepsilon_{2}(t)$ 는 자기상관이 존재하지 않는 백색잡음이고, 또 $\alpha_{11}(0)$ 과 $\alpha_{21}(0)$ 은 각각 1 이다. 모든 시차 $k$ 에 대해 $\alpha_{22}(k) \neq 0$ 이고 $\alpha_{13}(k)=0$ 이면 $Z_{1}(t)$ 는 $Z_{2}(t)$ 의 예측에 유용하다.

셋째, 금리차의 시차변수를 설명변수로 사용하여 회귀분석을 실시, 미래의 경기동향을 어느 정도 예측 할 수 있는지 검정하는 방법으로 Harvey (1988), 또 Lee (2010) 등의 연구가 있다. 시차별 회귀분석은 아래와 같은 모형을 사용하여 경기지표의 한계변동에 대한 금리차의 시차별 예측력을 검정한다. 여기서 $y_{t}$ 는 경기지표, $x_{t}$ 는 장단기 금리차, $k$ 는 예측시계의 길이, $\beta$ 는 계수벡터 그리고 $\epsilon_{t}$ 는 정규분포 오차항 이다.

$$
y_{t+k}=\beta^{\prime} x_{t}+\epsilon_{t} .
$$

Stock과 Watson (1996)은 미국의 76 개 대표적 월간 거시경제 시계열을 사용하여 16 개의 다른 모형으 로 5700 이변량 예측관계를 비교, 검토한 결과 많은 일변량과 이변량 자기회귀모형에 상당한 불안정성 이 존재하는 것으로 검정되었다. Stock과 Watson (2002a)은 주성분 분석에 의해 구축된 소수의 지수로 요약한 215 개 예측량을 사용하여 미국의 거시경제 시계열에 대한 $6,12,24$ 개월 앞의 예측을 실시한 결 과 일변량 자기회귀, 소형 벡터자기회귀, 또 선행지표 모형을 사용한 경우에 비해 우월한 것으로 나타났 다. 추가로 Stock과 Watson (2002b)은 다수의 예측량과 시계열 관측값으로 한 시계열을 예측하는 방 식에 대해 연구하였으며 타당한 예측과 그렇지 않은 예측의 차가 예측량과 관측값의 수가 증가함에 따라 확률 0 으로 수렴한다는 관점에서 타당한 예측은 점근적 효율성을 유지하는 것으로 나타났다.

예측을 유발하는 통계모형은 아래와 같은 형식으로 요약할 수 있다. $y_{t+1}$ 이 예측할 상수계열, 또 $x$ 가 $t=1, \ldots, T$ 동안 관측된 설명변수들의 $N$ 차 중시계열일 때 $\bar{r}$ 개의 공통 동적 요인 $\left\{f_{t}\right\}$ 를 가진 이들의 관계는 $i=1,2, \ldots, N$ 에 대해 다음과 같은 동태모형으로 나타난다.

$$
\begin{aligned}
y_{t+1} & =\beta(L) f_{t}+\gamma(L) y_{t}+\epsilon_{t+1}, \\
x_{i t} & =\lambda_{i}(L) f_{t}+e_{i t},
\end{aligned}
$$

여기서 $e_{i t}=\left(e_{i t}, \cdot, e_{N t}\right)^{\prime}$ 는 $N \times 1$ 교란항, 또 $\lambda_{i}(L)$ 과 $\beta(L)$ 은 다항시차이고 $E\left(\epsilon_{t+1} \mid f_{t}, y_{t}, x_{t}, f_{t-1}\right.$, $\left.y_{t-1}, x_{t-1}, \ldots\right)=0$ 을 가정한다. 따라서 $\left\{f_{t}\right\}, \beta(L)$ 과 $\gamma(L)$ 을 알면 $y_{t+1}$ 의 최소평균제곱오차 예측은 $\beta(L) f_{T}+\gamma(L) y_{T}$ 가 된다. 여기서 다항시차항들을 최대 $q$ 까지 유한시차를 갖는 것으로 모형화된다고 가정하면 식 (2.1)과 식 (2.2)는 아래와 같이 쓸 수 있다.

$$
\begin{aligned}
y_{t+1} & =\beta^{\prime} F_{t}+\gamma(L) y_{t}+\epsilon_{t+1}, \\
x_{t} & =\Lambda F_{t}+e_{t} .
\end{aligned}
$$

이때 $F_{t}=\left(f_{t}^{\prime}, \ldots, f_{t-q}^{\prime}\right)$ 는 $r \times 1, r \leq(q+1) \bar{r}, \Lambda$ 의 $i$ 번째 행은 $\left(\lambda_{i 0}, \ldots, \lambda_{i q}\right)$, 그리고 $\beta=$ $\left(\beta_{0}, \ldots, \beta_{q}\right)^{\prime}$ 이다. 실제 다단계 예측에 적용해 보고자 $h$ 단계 앞을 예측한다면 식 (2.3)은 식 (2.5)와 같이 수정되며 여기서 $y_{t+h}^{h}$ 는 예측해야 할 $h$ 단계 앞의 변수이고 상수항이 추가 된다.

$$
y_{t+h}^{h}=\alpha_{h}+\beta_{h}(L) F_{t}+\gamma_{h}(L) y_{t}+\epsilon_{t+h}^{h} .
$$

Rudebusch 등 (2007)와 Kim 등 (2011)는 미래 성장률 예측함수를 이용하여 장단기 금리차와 이를 분 해한 미래의 기대 단기금리 및 기간프리미엄의 미래 경기변동에 대한 연관성을 아래와 같은 형의 모형을 
사용하여 분석하였다.

$$
\begin{aligned}
& y_{t+12}-y_{t}=\beta_{0}+\beta_{1}\left(y_{t}-y_{t-12}\right)+\beta_{2}\left(r_{t}^{n}-r_{t}^{s}\right)+\epsilon_{t}, \\
& y_{t+12}-y_{t}=\beta_{0}+\beta_{1}\left(y_{t}-y_{t-12}\right)+\beta_{2} E\left(R_{t}\right)+\beta_{3} \mathrm{TP}_{t}+\epsilon_{t} .
\end{aligned}
$$

식 (2.6)과 식 (2.7)에서 좌변은 1 년 후 경제성장, 우변의 $y_{t}-y_{t-12}$ 는 현재 경제성장(전년 동월비), $\left(r_{t}^{n}-r_{t}^{s}\right)$ 는 장단기 금리차, $E\left(R_{t}\right)$ 는 미래의 기대 단기금리, $\mathrm{TP}_{t}$ 는 기간프리미엄이다.

특정 변수가 정보변수로 활용되기 위해서는 유의한 선행정보를 제공할 수 있는 예측력을 지녀야 한다. 따라서 실제의 장단기 금리차가 실질 성장에 예측력을 갖는지, 즉 장단기 금리차만으로도 미래의 성장에 대해 통계적으로 유의한 설명력을 갖는지를 검정한다. 시차별 회귀분석이 주로 종속변수의 한계변동에 대한 독립변수의 시차별 예측력을 추정하는 데 반해 본 연구에서는 앞의 연구들을 참고로 실질 국내총생 산(GDP)의 누적변동치에 대한 금리차의 예측력을 추정하며 아래와 같은 연률화된 누적변화율을 사용 하기로 한다.

$$
\begin{aligned}
Z_{t, t+m} & =\left(\frac{400}{m}\right)\left[\log \left(\frac{z_{t+m}}{z_{t}}\right)\right] \\
& =\left(\frac{400}{m}\right)\left(\log z_{t+m}-\log z_{t}\right),
\end{aligned}
$$

여기서 $m$ 은 예측시계, $z_{t+m}$ 은 기간 $t+m$ 의 실질 $\mathrm{GDP}$, 또 $Z_{t, t+m}$ 은 현 기간 $t$ 에서 미래 기간 $t+m$ 까지 의 누적변화이다. 미래 성장에 대한 누적적 예측력을 검정하기 위한 모형은 아래와 같이 설정하고 $X_{i t}$ 는 기간 $t$ 의 장단기 금리차를 나타낸다.

$$
Z_{t, t+m}=\alpha_{0}+\alpha_{1} X_{i t}+\epsilon_{t}
$$

\section{3. 자료}

$\mathrm{GDP}$ 는 가장 대표적인 실물경제지표로 전체 성장을 나타내는 참고변수로 사용될 수 있으며, 특히 GDP 성장률은 경기변동과 단.장기 특성을 파악하는데 사용된다 (Moon, 2011; Baek과 Kim, 2012). GDP는 다른 복합경기지표 보다도 현실상황을 잘 반영하는 것으로 알려져 있으나 자료가 분기별로 발표되므로 관측값이 충분하지 않거나 월 변동을 분석할 때는 통계청의 월간 산업동향에서 발표되는 산업생산지수 나 경기동행지수 등을 대체지표로 흔히 사용한다. 그러나 산업생산지수는 총체적 경제활동의 지표로 사 용되기에는 충분한 정보를 갖추고 있지 못하고, 경기동행지수는 계절, 불규칙, 추세 요인 등을 제거하 는 과정에서 중요 정보가 훼손될 우려가 있다. Moon (2011)은 상태공간법에 의한 시간분할을 사용하여 월 GDP를 추정하였다. 금리가 안정세를 회복한 1999 년 1 분기부터 2011 년 4 분기까지 총 52 개 분기 동 안 국내 대표적 금리로서 3 년 만기 회사채 수익률과 콜금리의 차 $\left(X_{1}\right), 5$ 년 만기 국민주택채권 수익률과 1 년 만기 통안증권 수익률의 차 $\left(X_{2}\right)$, 또 3 년 만기 회사채 수익률과 91 일 $\mathrm{CD}$ 유통 수익률의 차 $\left(X_{3}\right)$ 등 세 가지 장단기 금리차를 이용하여 경기 예측력에 대한 실증적 검정을 수행한다. 모든 자료는 한국은행 경제통계시스템에서 제공되는 자료이며, 금리는 분기별 평균값이다.

회사채 수익률은 일반인들이 회사채를 만기까지 보유했을 때 받을 수 있는 투자수익을 말하며, 이를 당 초 투자금액으로 나누고 다시 연이율 개념으로 환산한 것으로 유통수익률과 발행수익률로 대별되는 데 유통수익률은 시중 실세금리의 대표지표로 활용되고 있다. 콜금리는 금융기관 간 이루어지는 초단기 대 차에 적용되는 금리로 1 일 금리를 의미하며 $\mathrm{CD}$ (양도성 예금증서 $)$ 유통수익률과 같은 단기금리, 또 회 사채 유통수익률등과 함께 시중의 자금사정을 반영하는 지표로 이용된다. 국민주택채권은 주택을 등기 
Table 3.1. Basic statistics

\begin{tabular}{cccc}
\hline & $X_{1}$ & $X_{2}$ & $X_{3}$ \\
\hline Mean & 2.1965 & 0.8838 & 0.5696 \\
Median & 1.8150 & 0.7100 & 0.5850 \\
Maximum & 5.1400 & 2.2700 & 2.9500 \\
Minimum & 0.4900 & 0.0900 & -2.0100 \\
Std. Dev. & 1.2755 & 0.5885 & 1.2293 \\
Skewness & 0.7856 & 0.8113 & -0.0242 \\
Kurtosis & 2.6039 & 2.6581 & 2.1636 \\
Jarque-Bera & 5.6885 & 5.9571 & 1.5210 \\
Probability & 0.0582 & 0.0509 & 0.4674 \\
Sum & 114.2200 & 45.9600 & 29.6200 \\
Sum Sq. Dev. & 82.9774 & 17.6644 & 77.0646 \\
Observations & 52 & 52 & 52 \\
\hline
\end{tabular}

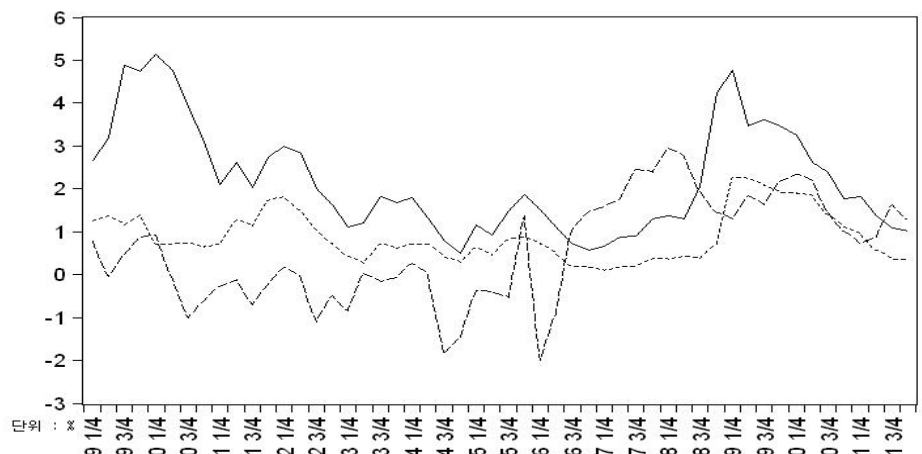

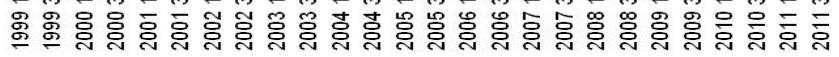

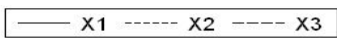

Figure 3.1. Data series of three variables

하거나 각종 인허가를 받을 때 의무적으로 매입하는 첨가 소화형채권으로 주택은행이 발행을 맡고 있으 며 만기는 5 년 이자율은 연 $5 \%$ 이다. 통안증권은 한국은행이 시중 통화량을 조절할 목적으로 발행하는 특별 유통증권이며 무기명채로 발행이율은 한은총재가 결정하지만 1993년 금리자유화 이후 시장실세금 리로 발행하고 있다.

Table 3.1에 요약된 각 변수의 기초통계량을 보면 자료의 정규성에 대한 검정은 시계열이 정규분포를 따 른다는 귀무가설이 $X_{1}$ 과 $X_{2}$ 의 경우 유의수준 $5 \%$ 남짓에서 기각된다. 또 왜도는 $X_{1}$ 과 $X_{2}$ 가 0 보다 크 므로 우측 꼬리가 긴 분포를 하고, 첨도는 모든 변수가 3 보다 작으므로 정규분포보다 완만한 분포를 따 른다는 사실을 알 수 있다.

장단기 금리차는 금융불안, 통화정책, 채권시장 수급여건 등에 영향을 주는 요인의 변화에 따라서도 크 게 변동한다. 즉 2001년 9.11 사태, 2003년 카드사태, 2008년 글로벌 금융위기사태 등 국내외 금융시장 의 불안이 증폭된 시기에 장기금리의 급등으로 장단기 금리차가 크게 확대되었다가 이후 불확실성이 해 소되면서 점차 축소되는 모습을 보여왔다. 예를 들어 글로벌 금융위기 여파로 장단기 금리차는 2009년 초부터 크게 확대되었으나 2010 년 4 월 이후 빠르게 축소되었다. Figure 3.1 의 시계열도는 이러한 사실 을 보여준다. 
Table 4.1. Predicting future changes in real growth $\left(X_{1}\right)$

\begin{tabular}{|c|c|c|c|c|c|}
\hline$m$ periods ahead & nobs & $\alpha_{0}$ & $\alpha_{1}$ & $\bar{R}^{2}$ & SEE \\
\hline 1 & 51 & $\begin{array}{c}0.971 \\
(0.461)^{* *}\end{array}$ & $\begin{array}{c}0.462 \\
(0.180)^{* *}\end{array}$ & 0.049 & 2.209 \\
\hline 2 & 50 & $\begin{array}{c}1.015 \\
(0.585)^{*}\end{array}$ & $\begin{array}{l}0.422 \\
(0.195)^{* *}\end{array}$ & 0.078 & 1.669 \\
\hline 3 & 49 & $\begin{array}{l}1.180 \\
(0.572)^{* *}\end{array}$ & $\begin{array}{c}0.336 \\
(0.186)^{*}\end{array}$ & 0.069 & 1.402 \\
\hline 4 & 48 & $\begin{array}{l}1.306 \\
(0.507)^{* *}\end{array}$ & $\begin{array}{c}0.266 \\
(0.160)\end{array}$ & 0.063 & 1.165 \\
\hline 5 & 47 & $\begin{array}{l}1.348 \\
(0.463)^{* * *}\end{array}$ & $\begin{array}{c}0.235 \\
(0.142)\end{array}$ & 0.071 & 0.981 \\
\hline 6 & 46 & $\begin{array}{l}1.317 \\
(0.411)^{* * *}\end{array}$ & $\begin{array}{c}0.242 \\
(0.124)^{*}\end{array}$ & 0.119 & 0.808 \\
\hline 7 & 45 & $\begin{array}{l}1.290 \\
(0.357)^{* * *}\end{array}$ & $\begin{array}{l}0.247 \\
(0.105)^{* *}\end{array}$ & 0.193 & 0.645 \\
\hline 8 & 44 & $\begin{array}{l}1.259 \\
(0.311)^{* * *}\end{array}$ & $\begin{array}{c}0.261 \\
(0.090)^{* * *}\end{array}$ & 0.273 & 0.557 \\
\hline 12 & 40 & $\begin{array}{l}1.414 \\
(0.212)^{* * *}\end{array}$ & $\begin{array}{l}0.183 \\
(0.074)^{* *}\end{array}$ & 0.188 & 0.469 \\
\hline 16 & 36 & $\begin{array}{l}1.427 \\
(0.119)^{* * *}\end{array}$ & $\begin{array}{l}0.171 \\
(0.042)^{* * *}\end{array}$ & 0.376 & 0.282 \\
\hline 20 & 32 & $\begin{array}{l}1.532 \\
(0.108)^{* * *}\end{array}$ & $\begin{array}{l}0.122 \\
(0.040)^{* * *}\end{array}$ & 0.238 & 0.274 \\
\hline
\end{tabular}

\section{4. 예측력 검정}

Table 4.1 은 1 에서 20 기간 앞까지 장단기 금리차 $X_{1}$ 의 예측력에 대한 모형의 추정결과이다. 예측시계 $m$ 은 1 에서 20 기간 앞까지 변하므로 시계의 중복으로 인해 추정상 문제가 있다. 두 기간 이상의 시계 예 측에는 예측시계가 관측구간보다 길어 자료가 부분적으로 겹치면서 $m-1$ 차 이동평균오차항이 발생한 다 (Estrella와 Mishkin, 1998). 그 결과 예측오차 간 자기상관으로 인해 통상적 검정통계량을 사용하 는 개별 변수들의 유의성 추정값에 오류가 존재할 가능성이 높아진다. 이 경우 OLS 회귀계수의 일치성 에는 영향을 미치지 않으나 OLS 표준오차의 일치성에는 영향을 미치게 된다 (Newey와 West, 1987). 정확한 통계적 추론을 위해 OLS 표준오차가 조정되어야 하며, 따라서 이분산 및 자기상관을 고려하는 Newey-West 방법을 적용함으로써 자료 중복 문제를 조정한 표준오차를 사용하여 $t$ 통계량을 계산한다. 부분적으로 겹치지 않은 자료는 자기상관 될 수 있다는 전제에서 이동평균의 차수 길이를 $m-1$ 보다 길게 잡는다. OLS 잔차의 추정 자기상관함수를 관찰, Newey-West 수정 시차길이를 선택하지만 수정 된 표준오차는 시차 길이에 민감하지 않다. 본 연구에서 $*, * *, * * *$ 는 각각 $10 \%, 5 \%, 1 \%$ 유의수준에서 통계적으로 유의함을 나타내며, ( )안은 Newey-West 수정 표준오차이다. nobs는 분기별 관측값의 수, $\bar{R}^{2}$ 은 수정 결정계수, 또 $\mathrm{SEE}$ 는 회귀표준오차이다.

Table 4.1 은 현 분기 장단기 금리차 $X_{1}$ 이 $1 \%$ 라면 한 기간 앞 실질 $\mathrm{GDP}$ 는 $1.433 \%(0.971 \%+0.462 \times$ $1 \%$ ), 또 두 기간 동안에는 $1.437 \%$ 성장할 것으로 예측됨을 보여준다. 절편 $\alpha_{0}$ 가 양수이므로 기울기 또 는 금리차가 음수라도 미래 실질 GDP가 반드시 음의 성장을 할 것으로 예측되지는 않는다. 두 분기 동 안의 누적성장에서 만약 금리차가 $-2.405 \%\left(0.422 X_{1}=-1.015 \%\right)$ 보다 작았다면 실질 $\mathrm{GDP}$ 는 음의 성장이 예측되었을 것이다. 누적변화에 대한 모형의 예측력은 첫 3 분기 동안 통계적으로 유의하게 지속 
Table 4.2. Predicting future changes in real growth $\left(X_{2}\right)$

\begin{tabular}{|c|c|c|c|c|c|}
\hline$m$ periods ahead & nobs & $\alpha_{0}$ & $\alpha_{1}$ & $\bar{R}^{2}$ & SEE \\
\hline 1 & 51 & $\begin{array}{c}0.728 \\
(0.684)\end{array}$ & $\begin{array}{c}1.418 \\
(0.562)^{* *}\end{array}$ & 0.118 & 2.127 \\
\hline 2 & 50 & $\begin{array}{c}0.978 \\
(0.631)\end{array}$ & $\begin{array}{c}1.085 \\
(0.511)^{* *}\end{array}$ & 0.118 & 1.632 \\
\hline 3 & 49 & $\begin{array}{c}1.163 \\
(0.540)^{* *}\end{array}$ & $\begin{array}{c}0.850 \\
(0.434)^{*}\end{array}$ & 0.102 & 1.377 \\
\hline 4 & 48 & $\begin{array}{c}1.309 \\
(0.470)^{* * *}\end{array}$ & $\begin{array}{c}0.659 \\
(0.372)^{*}\end{array}$ & 0.089 & 1.149 \\
\hline 5 & 47 & $\begin{array}{l}1.387 \\
(0.421)^{* * *}\end{array}$ & $\begin{array}{c}0.547 \\
(0.334)\end{array}$ & 0.086 & 0.974 \\
\hline 6 & 46 & $\begin{array}{l}1.418 \\
(0.370)^{* * *}\end{array}$ & $\begin{array}{c}0.501 \\
(0.293)^{*}\end{array}$ & 0.106 & 0.814 \\
\hline 7 & 45 & $\begin{array}{l}1.395 \\
(0.325)^{* * *}\end{array}$ & $\begin{array}{c}0.520 \\
(0.263)^{*}\end{array}$ & 0.168 & 0.655 \\
\hline 8 & 44 & $\begin{array}{c}1.389 \\
(0.285)^{* * *}\end{array}$ & $\begin{array}{c}0.535 \\
(0.242)^{* *}\end{array}$ & 0.211 & 0.580 \\
\hline 12 & 40 & $\begin{array}{l}1.417 \\
(0.215)^{* * *}\end{array}$ & $\begin{array}{c}0.524 \\
(0.304)^{*}\end{array}$ & 0.174 & 0.473 \\
\hline 16 & 36 & $\begin{array}{l}1.447 \\
(0.136)^{* * *}\end{array}$ & $\begin{array}{c}0.443 \\
(0.172)^{* *}\end{array}$ & 0.295 & 0.299 \\
\hline 20 & 32 & $\begin{array}{l}1.505 \\
(0.131)^{* * *}\end{array}$ & $\begin{array}{c}0.362 \\
(0.151)^{* *}\end{array}$ & 0.221 & 0.277 \\
\hline
\end{tabular}

되지만 특히 6 분기 앞부터는 매우 유의하게 지속되는 것으로 나타난다. $\overline{R^{2}}$ 는 표본 내 예측력의 정확도 에 대한 척도를 제공하며, $X_{1}$ 계수의 통계적 유의성은 실질 $\mathrm{GDP}$ 의 미래 변화의 방향을 예측하는데 있 어서 방정식의 신뢰도에 대한 정보를 제공해준다. 예측 정확도는 미래로 갈수록 상승하여 7 분기 앞을 넘어서면서부터 가장 높은 것으로 나타나며, 차분변수 관계임에도 일반적인 경우와는 달리 $R^{2}$ 값이 크게 하락하지 않고 금리차만으로도 실질 성장을 $30 \sim 40 \%$ 정도 설명하는 것으로 추정된다.

Table 4.2 는 금리차로 $X_{2}$ 가 사용되는 경우의 추정결과를 요약하며 모형은 거의 모든 기간 통계적으로 유의한 예측력을 제공함을 보여준다. 현 기간 장단기 금리차 $X_{2}$ 가 $1 \%$ 라면 실질 $\mathrm{GDP}$ 의 누적변화는 1 년에 걸쳐 $1.968 \%$ 성장할 것으로 예측되며, 2 년 앞부터는 $X_{2}$ 만으로도 누적변화를 최대 $30 \%$ 까지 설 명할 수 있는 것으로 추정된다. 반면 $X_{3}$ 의 경우 Table 4.3 에서 보듯이 모형은 가까운 미래와 먼 미래 의 누적변화에 대해 유의한 예측력을 갖지 못하며, 앞의 두 금리차의 경우와는 상반된 성향을 보인다. $X_{3}$ 은 음의 기울기를 가지는 것으로 추정되지만 앞의 경우보다는 큰 양의 절편값으로 인해 모형이 여전 히 미래 실질 GDP가 양의 성장을 하는 것으로 예측할 수 있게 된다.

미래의 실질 성장을 예측하는데 있어서 특정 금리차가 주는 정보에 더해 다른 성향의 금리차가 주는 추 가적인 정보도 존재하는가 검정하기로 하며, 별도의 정보가 존재하는 경우 이들의 비교가치를 판별해 보 기로 한다. 따라서 원래의 회귀방정식에 아래와 같이 다른 금리차를 추가하여 두 변수가 다양한 예측시 계에서 지속해서 통계적으로 유의한 계수를 갖는지를 검정한다.

$$
Z_{t, t+m}=\alpha_{0}+\sum_{i=1}^{2} \alpha_{i} X_{i t}+\epsilon_{t}
$$


Table 4.3. Predicting future changes in real growth $\left(X_{3}\right)$

\begin{tabular}{|c|c|c|c|c|c|}
\hline$m$ periods ahead & nobs & $\alpha_{0}$ & $\alpha_{1}$ & $\bar{R}^{2}$ & SEE \\
\hline 1 & 51 & $\begin{array}{l}2.038 \\
(0.306)^{* * *}\end{array}$ & $\begin{array}{c}-0.076 \\
(0.284)\end{array}$ & 0.019 & 2.286 \\
\hline 2 & 50 & $\begin{array}{l}2.082 \\
(0.276)^{* * *}\end{array}$ & $\begin{array}{c}-0.227 \\
(0.300)\end{array}$ & 0.006 & 1.733 \\
\hline 3 & 49 & $\begin{array}{l}2.093 \\
(0.244)^{* * *}\end{array}$ & $\begin{array}{c}-0.293 \\
(0.283)\end{array}$ & 0.044 & 1.421 \\
\hline 4 & 48 & $\begin{array}{l}2.074 \\
(0.206)^{* * *}\end{array}$ & $\begin{array}{c}-0.304 \\
(0.232)\end{array}$ & 0.090 & 1.148 \\
\hline 5 & 47 & $\begin{array}{l}2.043 \\
(0.171)^{* * *}\end{array}$ & $\begin{array}{r}-0.310 \\
(0.186)\end{array}$ & 0.132 & 0.949 \\
\hline 6 & 46 & $\begin{array}{l}2.006 \\
(0.142)^{* * *}\end{array}$ & $\begin{array}{c}-0.280 \\
(0.149)^{*}\end{array}$ & 0.155 & 0.791 \\
\hline 7 & 45 & $\begin{array}{l}1.969 \\
(0.125)^{* * *}\end{array}$ & $\begin{array}{l}-0.261 \\
(0.123)^{* *}\end{array}$ & 0.194 & 0.645 \\
\hline 8 & 44 & $\begin{array}{l}1.940 \\
(0.121)^{* * *}\end{array}$ & $\begin{array}{l}-0.230 \\
(0.104)^{* *}\end{array}$ & 0.176 & 0.592 \\
\hline 12 & 40 & $\begin{array}{l}1.833 \\
(0.133)^{* * *}\end{array}$ & $\begin{array}{c}-0.128 \\
(0.077)\end{array}$ & 0.069 & 0.502 \\
\hline 16 & 36 & $\begin{array}{l}1.784 \\
(0.100)^{* * *}\end{array}$ & $\begin{array}{c}-0.049 \\
(0.081)\end{array}$ & 0.007 & 0.358 \\
\hline 20 & 32 & $\begin{array}{l}1.810 \\
(0.099)^{* * *}\end{array}$ & $\begin{array}{c}0.038 \\
(0.072)\end{array}$ & 0.023 & 0.318 \\
\hline
\end{tabular}

앞의 표에서 사용된 장단기 금리차가 각각 실질 $\mathrm{GDP}$ 의 누적변화에 유의한 예측력을 갖는 것은 다른 기 간구조를 가진 변수들이 모형에 함께 포함되지 않음에 따라 이들의 성향이 갖는 정보가 사용된 변수에 내재된 결과 나타난 현상일 가능성이 있다. 따라서 다른 기간구조의 금리차를 함께 설명변수로 사용해 도 현 설명변수가 유의한 예측력을 갖는지 아니면 어떤 변화가 나타나는지 분석해 보기로 한다. 각각 사 용될 때 유의한 예측력을 갖는 변수들이 함께 포함되어도 유의하다면 각 기간구조가 특유의 자체 예측력 을 보유한다는 의미이다. 반면 각각 사용될 때는 실질 성장의 누적변화에 대해 유의한 예측력을 갖지만 동시에 사용될 때 어느 한 변수의 예측력이 약화된다면 이는 두 변수에 내재된 정보의 성향이 비슷해 한 쪽의 설명력이 잠식됨을 시사한다. Table 4.1 과 Table 4.2 에서 보듯이 $X_{1}$ 과 $X_{2}$ 를 개별적으로 사용하 면 대부분의 예측시계에서 통계적으로 유의한 예측력을 유지하지만 두 지표가 함께 설명변수로 사용될 때는 Table 4.4에서 보듯이 $X_{1}$ 만 6 기간 앞부터 유의한 예측력을 갖는 반면 $X_{2}$ 는 전체 예측시계에서 유 의한 설명력을 갖지 못하는 것으로 나타난다. 이는 국내 대표 금리인 3 년 만기 회사채 수익률과 콜금리 로 구성된 $X_{1}$ 이 지배변수로서 $X_{2}$ 가 가진 정보를 이미 포함하고 있음을 암시하며, 따라서 모형이 다중 공선성 정황을 보이므로 두 변수는 각각 사용되는 것이 예측에 더 유용함을 알 수 있다.

가장 보편적인 금리인 3 년 만기 회사채 수익률을 장기금리로 사용하는 경우를 비교하면 단기금리로 초 단기금리인 콜금리를 사용하는 $X_{1}$ 과 91 일 $\mathrm{CD}$ 유통수익률을 사용하는 $X_{3}$ 이 함께 설명변수로 포함되는 경우 추정결과는 Table 4.5 와 같이 요약된다. $X_{1}$ 은 단독으로 사용될 경우에도 거의 모든 예측시계에서 실질 성장을 통계적으로 유의하게 예측하지만 $X_{3}$ 과 함께 사용되면 설명력이 강화되어 전체 예측시계에 걸쳐 유의한 예측력을 갖는다. 반면 $X_{3}$ 은 여전히 가까운 미래와 먼 미래의 변동에 대해서는 유의한 예 측력을 갖지 못하는 것으로 추정되지만 단독으로 사용되었을 때에 비해 $X_{1}$ 과 함께 사용될 때는 더 많은 
Table 4.4. Predicting future changes in real growth $\left(X_{1}\right.$ and $\left.X_{2}\right)$

\begin{tabular}{|c|c|c|c|c|c|c|}
\hline$m$ periods ahead & nobs & $\alpha_{0}$ & $\alpha_{1}$ & $\alpha_{2}$ & $\bar{R}^{2}$ & SEE \\
\hline 1 & 51 & $\begin{array}{c}0.664 \\
(0.627)\end{array}$ & $\begin{array}{c}0.066 \\
(0.328)\end{array}$ & $\begin{array}{c}1.325 \\
(0.819)\end{array}$ & 0.101 & 2.148 \\
\hline 2 & 50 & $\begin{array}{c}0.810 \\
(0.684)\end{array}$ & $\begin{array}{c}0.172 \\
(0.184)\end{array}$ & $\begin{array}{c}0.846 \\
(0.558)\end{array}$ & 0.109 & 1.640 \\
\hline 3 & 49 & $\begin{array}{c}1.020 \\
(0.629)\end{array}$ & $\begin{array}{c}0.144 \\
(0.152)\end{array}$ & $\begin{array}{c}0.651 \\
(0.419)\end{array}$ & 0.092 & 1.384 \\
\hline 4 & 48 & $\begin{array}{l}1.188 \\
(0.546)^{* *}\end{array}$ & $\begin{array}{c}0.120 \\
(0.123)\end{array}$ & $\begin{array}{c}0.493 \\
(0.347)\end{array}$ & 0.079 & 1.155 \\
\hline 5 & 47 & $\begin{array}{c}1.262 \\
(0.488) * *\end{array}$ & $\begin{array}{c}0.123 \\
(0.100)\end{array}$ & $\begin{array}{c}0.375 \\
(0.305)\end{array}$ & 0.081 & 0.977 \\
\hline 6 & 46 & $\begin{array}{l}1.257 \\
(0.427)^{* * *}\end{array}$ & $\begin{array}{c}0.160 \\
(0.095)^{*}\end{array}$ & $\begin{array}{c}0.275 \\
(0.265)\end{array}$ & 0.121 & 0.807 \\
\hline 7 & 45 & $\begin{array}{c}1.233 \\
(0.367)^{* * *}\end{array}$ & $\begin{array}{c}0.166 \\
(0.078)^{* *}\end{array}$ & $\begin{array}{c}0.276 \\
(0.230)\end{array}$ & 0.205 & 0.641 \\
\hline 8 & 44 & $\begin{array}{c}1.206 \\
(0.318)^{* * *}\end{array}$ & $\begin{array}{c}0.190 \\
(0.067)^{* * *}\end{array}$ & $\begin{array}{c}0.248 \\
(0.202)\end{array}$ & 0.284 & 0.552 \\
\hline 12 & 40 & $\begin{array}{c}1.318 \\
(0.231)^{* * *}\end{array}$ & $\begin{array}{c}0.121 \\
(0.062)^{*}\end{array}$ & $\begin{array}{c}0.312 \\
(0.287)\end{array}$ & 0.214 & 0.462 \\
\hline 16 & 36 & $\begin{array}{l}1.356 \\
(0.126)^{* * *}\end{array}$ & $\begin{array}{c}0.124 \\
(0.032)^{* * *}\end{array}$ & $\begin{array}{c}0.223 \\
(0.155)\end{array}$ & 0.409 & 0.274 \\
\hline 20 & 32 & $\begin{array}{c}1.439 \\
(0.122)^{* * *}\end{array}$ & $\begin{array}{c}0.082 \\
(0.026)^{* * *}\end{array}$ & $\begin{array}{c}0.222 \\
(0.136)\end{array}$ & 0.281 & 0.267 \\
\hline
\end{tabular}

기간 더 유의한 예측력을 갖는 것으로 나타난다. 따라서 각각 사용될 때 존재하지 않았던 두 변수 간 상 호 보완작용이 함께 사용될 때 이루어짐을 시사한다. 이는 Table 4.4에서도 보았듯이 주로 경제·경영변 수 사용 시 흔히 발생하며 추정에 사용된 변수의 조합에 따라 상호 대체 또는 보완작용 등이 발생하여 계수들의 통계적 유의성이나 부호가 달라지기도 한다. 미래의 실질 성장에 대한 두 변수의 예측 정확도 는 6 에서 8 분기 앞이 가장 높아 모형은 미래 실질 GDP 변화의 절반가량을 설명한다.

만기가 긴 두 금리를 장기금리로 각각 사용한 두 금리차 $X_{2}$ 와 $X_{3}$ 을 함께 포함하는 경우 각 변수가 유의 한 예측력을 갖는가는 Table 4.6 과 같이 요약된다. $X_{2}$ 는 한 분기 앞부터 거의 모든 예측시계에 걸쳐 미 래의 실질 성장에 대해 유의한 예측력을 유지하는 반면 $X_{3}$ 은 초기와 후기에는 유의한 예측력을 갖지 못 하는 것으로 나타난다. $X_{2}$ 는 $X_{1}$ 과 함께 사용될 때와는 달리 $X_{3}$ 과 사용될 때는 전 예측시계에 걸쳐 유 의한 예측력을 회복하는 것으로 판명되어 $X_{2}$ 와 $X_{3}$ 에는 각각 별도의 정보가 존재함을 알려준다. $X_{3}$ 의 증가는 세 분기가 지나면서부터 2 년 앞까지 실질 성장의 감소를 유의하게 예측하여 이 경우 3 년 만기 회 사채 수익률과 $\mathrm{CD}$ 유통 수익률 간 차가 벌어질수록 1-2년 후 실질 성장을 저해할 가능성이 높아지게 된 다. 모형의 추정결과에 의하면 예측 정확도는 1 년 앞부터 2 년 앞까지 가장 높으며, 두 금리차 변수만으 로도 실질 누적성장의 $40 \%$ 이상까지 설명하는 것으로 추정된다. $X_{3}$ 은 미래의 성장을 예측하는데 다른 변수들과는 이질적 성향을 보인다. 단독으로 사용될 때에 비해 다른 변수들과 함께 사용되면 예측력이 동반 향상되는 것으로 추정된다. 그러나 $X_{3}$ 자체는 추정과정에서 예측력이 높지 않은 것으로 나타나는 바 이는 $\mathrm{CD}$ 유통수익률에 그 원인이 있는 것으로 사료되지만 자세한 사항에 대해 알려지거나 연구된 바 는 없다. 
Table 4.5. Predicting future changes in real growth $\left(X_{1}\right.$ and $\left.X_{3}\right)$

\begin{tabular}{|c|c|c|c|c|c|c|}
\hline$m$ periods ahead & nobs & $\alpha_{0}$ & $\alpha_{1}$ & $\alpha_{3}$ & $\bar{R}^{2}$ & SEE \\
\hline 1 & 51 & $\begin{array}{c}1.013 \\
(0.417)^{* *}\end{array}$ & $\begin{array}{c}0.474 \\
(0.199)^{* *}\end{array}$ & $\begin{array}{r}-0.125 \\
(0.281)\end{array}$ & 0.034 & 2.227 \\
\hline 2 & 50 & $\begin{array}{c}1.093 \\
(0.521)^{* *}\end{array}$ & $\begin{array}{c}0.454 \\
(0.235)^{*}\end{array}$ & $\begin{array}{r}-0.282 \\
(0.299)\end{array}$ & 0.100 & 1.649 \\
\hline 3 & 49 & $\begin{array}{c}1.268 \\
(0.480)^{* *}\end{array}$ & $\begin{array}{c}0.376 \\
(0.220)^{*}\end{array}$ & $\begin{array}{r}-0.340 \\
(0.271)\end{array}$ & 0.137 & 1.350 \\
\hline 4 & 48 & $\begin{array}{c}1.394 \\
(0.391)^{* * *}\end{array}$ & $\begin{array}{c}0.309 \\
(0.182)^{*}\end{array}$ & $\begin{array}{r}-0.353 \\
(0.212)\end{array}$ & 0.184 & 1.087 \\
\hline 5 & 47 & $\begin{array}{c}1.427 \\
(0.326)^{* * *}\end{array}$ & $\begin{array}{c}0.279 \\
(0.150)^{*}\end{array}$ & $\begin{array}{l}-0.347 \\
(0.158)^{* *}\end{array}$ & 0.245 & 0.885 \\
\hline 6 & 46 & $\begin{array}{c}1.384 \\
(0.263)^{* * *}\end{array}$ & $\begin{array}{c}0.281 \\
(0.117)^{* *}\end{array}$ & $\begin{array}{l}-0.317 \\
(0.111)^{* * *}\end{array}$ & 0.328 & 0.706 \\
\hline 7 & 45 & $\begin{array}{c}1.347 \\
(0.201)^{* * *}\end{array}$ & $\begin{array}{c}0.281 \\
(0.085)^{* * *}\end{array}$ & $\begin{array}{l}-0.297 \\
(0.076)^{* * *}\end{array}$ & 0.459 & 0.529 \\
\hline 8 & 44 & $\begin{array}{c}1.312 \\
(0.170)^{* * *}\end{array}$ & $\begin{array}{c}0.285 \\
(0.064)^{* * *}\end{array}$ & $\begin{array}{l}-0.261 \\
(0.057)^{* * *}\end{array}$ & 0.515 & 0.454 \\
\hline 12 & 40 & $\begin{array}{c}1.454 \\
(0.182)^{* * *}\end{array}$ & $\begin{array}{c}0.181 \\
(0.068)^{* *}\end{array}$ & $\begin{array}{c}-0.124 \\
(0.067)^{*}\end{array}$ & 0.258 & 0.448 \\
\hline 16 & 36 & $\begin{array}{c}1.430 \\
(0.112)^{* * *}\end{array}$ & $\begin{array}{c}0.171 \\
(0.041)^{* * *}\end{array}$ & $\begin{array}{r}-0.049 \\
(0.042)\end{array}$ & 0.380 & 0.281 \\
\hline 20 & 32 & $\begin{array}{c}1.521 \\
(0.120)^{* * *}\end{array}$ & $\begin{array}{l}0.126 \\
(0.040)^{* * *}\end{array}$ & $\begin{array}{r}-0.019 \\
(0.048)\end{array}$ & 0.215 & 0.279 \\
\hline
\end{tabular}

Table 4.6. Predicting future changes in real growth $\left(X_{2}\right.$ and $\left.X_{3}\right)$

\begin{tabular}{|c|c|c|c|c|c|c|}
\hline$m$ periods ahead & nobs & $\alpha_{0}$ & $\alpha_{2}$ & $\alpha_{3}$ & $\bar{R}^{2}$ & SEE \\
\hline 1 & 51 & $\begin{array}{c}0.779 \\
(0.624)\end{array}$ & $\begin{array}{c}1.468 \\
(0.606)^{* *}\end{array}$ & $\begin{array}{r}-0.173 \\
(0.281)\end{array}$ & 0.109 & 2.138 \\
\hline 2 & 50 & $\begin{array}{c}1.052 \\
(0.554)^{*}\end{array}$ & $\begin{array}{l}1.190 \\
(0.557)^{* *}\end{array}$ & $\begin{array}{r}-0.316 \\
(0.289)\end{array}$ & 0.151 & 1.601 \\
\hline 3 & 49 & $\begin{array}{c}1.243 \\
(0.434)^{* * *}\end{array}$ & $\begin{array}{l}0.975 \\
(0.453)^{* *}\end{array}$ & $\begin{array}{r}-0.367 \\
(0.256)\end{array}$ & 0.184 & 1.313 \\
\hline 4 & 48 & $\begin{array}{c}1.388 \\
(0.337)^{* * *}\end{array}$ & $\begin{array}{c}0.787 \\
(0.368)^{* *}\end{array}$ & $\begin{array}{c}-0.374 \\
(0.199)^{*}\end{array}$ & 0.226 & 1.059 \\
\hline 5 & 47 & $\begin{array}{c}1.463 \\
(0.261)^{* * *}\end{array}$ & $\begin{array}{c}0.668 \\
(0.297)^{* *}\end{array}$ & $\begin{array}{c}-0.361 \\
(0.149)^{* *}\end{array}$ & 0.274 & 0.868 \\
\hline 6 & 46 & $\begin{array}{c}1.487 \\
(0.199)^{* * *}\end{array}$ & $\begin{array}{c}0.602 \\
(0.225)^{* *}\end{array}$ & $\begin{array}{l}-0.322 \\
(0.111)^{* * *}\end{array}$ & 0.320 & 0.710 \\
\hline 7 & 45 & $\begin{array}{c}1.469 \\
(0.157)^{* * *}\end{array}$ & $\begin{array}{c}0.585 \\
(0.173)^{* * *}\end{array}$ & $\begin{array}{l}-0.290 \\
(0.081)^{* * *}\end{array}$ & 0.421 & 0.547 \\
\hline 8 & 44 & $\begin{array}{l}1.467 \\
(0.146)^{* * *}\end{array}$ & $\begin{array}{c}0.562 \\
(0.158)^{* * *}\end{array}$ & $\begin{array}{l}-0.244 \\
(0.065)^{* * *}\end{array}$ & 0.421 & 0.497 \\
\hline 12 & 40 & $\begin{array}{c}1.487 \\
(0.226)^{* * *}\end{array}$ & $\begin{array}{c}0.460 \\
(0.322)\end{array}$ & $\begin{array}{r}-0.085 \\
(0.080)\end{array}$ & 0.191 & 0.468 \\
\hline 16 & 36 & $\begin{array}{c}1.453 \\
(0.141)^{* * *}\end{array}$ & $\begin{array}{c}0.436 \\
(0.182)^{* *}\end{array}$ & $\begin{array}{r}-0.016 \\
(0.051)\end{array}$ & 0.276 & 0.303 \\
\hline 20 & 32 & $\begin{array}{l}1.510 \\
(0.134)^{* * *}\end{array}$ & $\begin{array}{c}0.359 \\
(0.148)^{* *}\end{array}$ & $\begin{array}{c}0.011 \\
(0.043)\end{array}$ & 0.195 & 0.282 \\
\hline
\end{tabular}




\section{5. 결언}

정부의 공공정책은 최종 목표에 직접 영향을 주기보다는 정책수단을 사용하여 간접적인 영향력만 발휘 할 수 있으며 최종 목표에 영향을 미치기까지는 시차가 존재한다. 이에 따라 최종 목표와 선행적 상관관 계를 가지는 지표로 최종 목표의 미래 상황을 예측할 수 있는 정보변수를 개발하여 정책의 효율성을 높 이려는 방법이 모색된다. 장단기 금리차는 미래 경기동향의 예측에 유용한 정보를 제공하는 것으로 알 려져 있으며 경기 예측을 위한 선행지표로 활용되어 왔다. 본 연구는 국내에서 가장 보편적으로 사용되 는 기간구조를 가진 국내 장단기 금리차가 실질 성장의 누적변화에 대해 다양한 시계에서 유의한 예측력 을 갖는지 통계적으로 검정해 보았다. 시차별 분석 결과 대부분의 장단기 금리차가 미래의 누적 성장을 유의하게 예측하는 것으로 검정되어 현 시점의 금리차가 미래의 성장 및 경기동향 예측에 유용한 정보 변수 임이 입증된다. 추정결과는 장단기 금리차의 증가가 미래의 성장 가능성을 예측하지만 단기금리로 $\mathrm{CD}$ 유통 수익률을 사용하는 경우에 한해서는 미래에 성장이 둔화될 가능성을 시사한다. 실질 소득의 누 적변화를 예측하는데 있어서 특정 금리차가 주는 정보에 더해 다른 기간구조를 가진 금리차도 자체의 설 명력이 추가적으로 존재하는지 검정한 결과 두 금리차가 함께 사용될 때는 가까운 미래와 먼 미래에 대 해서는 동시에 유의한 예측력을 갖지 못하는 것으로 나타났다.

\section{References}

Baek, M. and Kim, W. (2012). Investigation on Granger causality between economic growth and demand for electricity in Korea: Using quarterly data, The Korean Journal of Applied Statistics, 25, 89-99.

Boldin, M. D. (1994). Dating turning points in the business cycle, Journal of Business, 67, 97-131.

Estrella, A. and Mishkin, F. S. (1996). The yield curve as a predictor of U.S. recession, Current Issues in Economics and Finance, 2, 1-6.

Estrella, A. and Mishkin, F. S. (1998). Predicting U.S. recessions: Financial variables as leading indicators, Review of Economics and Statistics, 80, 45-61.

Granger, C. W. J. (1986). Development in the study of cointegrated economic variable, Oxford Bulletin of Economics and Statistics, 48, 213-228.

Harvey, C. R. (1988). The real term structure and consumption growth, Journal of Financial Economics, 22, 305-333

Kim, J., Kim, D. and Jung, I. (2011). Analyzing factors of changes in interest rate term structure, $B O K$ Economy Brief, Bank of Korea, 2011-2.

Kim, T. H. and Song, D. S. (2009). The term structure and predicting the domestic recessions, The Korean Journal of Applied Statistics, 22, 249-260.

Kim, Y., Park, Y. S. and Lee, J.-J. (2004). An empirical test on the effectiveness of market timing strategies based on term premiums, Korea Journal of Financial Studies, 33, 135-173.

Lee, H.-S. (2010). A study on the predictability of economy by the long and short term interest spread of KRW interest rate swap, Journal of Industrial Economics and Business, 23, 3247-3269.

Lee, M. H. (1996). Role of long and short-run interest rate in monetary policy, The Bank of Korea, Economic Research Institute Economic Papers, 2, 107-132.

Moon, H. (2011). Construction of an economic sentiment indicator for the Korean economy, The Korean Journal of Applied Statistics, 24, 745-758.

Newey, W. K. and West, K. D. (1987). A Simple positive semi-definite, heteroskedasticity and autocorrelation consistent covariance matrix, Econometrica, 55, 703-708.

Oh, J. (1997). Interest rate spreads and monetary policy in Korea, The Bank of Korea, Economic Research Institute Economic Papers, 3, 1-46.

Resnick, B. G. and Shoesmith, G. L. (2002). Using the yield curve to time the stock market, Financial Analysts Journal, 58, 82-90.

Rudebusch, G. D., Sack, B. P. and Swanson, E. T. (2007). Macro-economic implications of changes in the term premium, Federal Reserve Bank of St. Louis Review, 89, 241-269. 
Smith, J. and Naylor, R. (2001). Determining of degree performance in UK universities: A statistical analysis of the 1993 student cohort, Oxford Bulletin of Economics and Statistics, 63, 29-60.

Stock, J. H. and Watson, M. W. (1996). Evidence on structural instability in macroeconomic time series relations, Journal of Business and Economic Statistics, 14, 11-30.

Stock, J. H. and Watson, M. W. (2002a). Macroeconomic forecasting using diffusion indexes, Journal of Business and Economic Statistics, 20, 147-162.

Stock, J. H. and Watson, M. W. (2002b). Forecasting using principal components from a large number of predictors, Journal of the American Statistical Association, 97, 1167-1179. 


\title{
실질 성장의 미래 변화 예측을 위한 정보변수
}

\author{
김태호 ${ }^{a, 1} \cdot$ 정재화 $^{a} \cdot$ 김민정 ${ }^{a}$ \\ $a$ 충북대학교 정보통계학과
}

(2012년 12월 14일 접수, 2013년 2월 15일 수정, 2013년 2월 26일 채택)

$$
\text { 요 약 }
$$

특정 정책이나 전략목표를 달성하는데 있어서 정부가 최종 목표에 직접 영향을 미치기는 어려워서 정책수단을 통해 간접적인 영향력만 발휘하게 되므로 최종 목표의 미래 동향을 예측할 수 있는 유용한 정보변수의 개발에 관심을 가지 게 된다. 금리의 기간구조는 미래 경기 동향의 예측에 유용한 정보를 주는 것으로 알려져 있으나 이에 대한 연구는 아직 부족한 실정이다. 본 연구에서는 국내 장단기 금리차가 장기 시계에서 실질 성장의 누적변화를 유의하게 예측 할 수 있는지 통계모형을 설정하여 분석해 보았다.

주요용어: 정보변수, 예측력, 기간구조.

1교신저자: (361-763) 충북 청주시 흥덕구 성봉로 410 , 충북대학교 정보통계학과, 교수.

E-mail: thkim@chungbuk.ac.kr 